the establishment were examined and diphtheria bacilli detected in the throat of the cook alone. On being questioned, she admitted having been to a neighbouring town some three or four days previously. While there she had been in contact with a case of diphtheria. The cook herself was in perfect health. In another instance a child with nasal diphtheria had infected six out of eight members of his class, in addition to his father, mother, and all his brothers and sisters, before he was found out. The mother said that the child had had a "stuffy cold in the head" for some three weeks or more. This one unsuspected case was responsible for no less than sixty-four cases of clinical diphtheria. Epidemics, further, are occasionally due to the infection of milk, in which medium the bacillus of the disease grows readily. An excellent example, somewhat too long for reproduction here, emphasises the importance of this avenue. Toys alone, such as india-rubber or other dolls, are very liable to hand on the infection from hand to mouth. Bad drainage and other un-hygienic conditions of life can only be regarded, in the light of bacteriological researches, as contributory causes, active on account of the lowered state of health resulting: from them. As regards treatment, the first essential is the early recognition of the disease in order to secure the early administration of the antitoxin. The antitoxin can only antagonise the poison of the bacillus before it has undergone chemical union with the tissues, and therefore postponement of the administration is fatal to success.

Mr. Hutchens deals at some length with the question of prophylaxis and the dosage of antitoxin, but space does not permit of an adequate allusion to some of the matters of importance touched upon under these headings. In general terms the paper under notice is a valuable exposition of the current attitude of the best opinion in the matter of diph-
theria.

\section{THE DRUG TREATMENT OF INEBRIETY.}

Dr. Jos. S. Bolton, ${ }^{1}$ writing of his own experience during the last twelve months in the drug treatment of inebriates, claims a record of distinct progress, though he declines to announce any "cure," as he considers this term should only be applied to an inebriate who, after treatment, has been an abstainer for at least two years. The following are some practical points to which Dr. Bolton draws attention. At first he used strychnine and atropine in what proved to be unnecessarily large doses, and the resulting dryness of the throat and difficulty of ment. solution of now limits the dose to one minim of solution of sulphate of atropine and four minims This he gives by of hydrochloride of strychnine. for a month by subcutaneous injection twice a day again every then once a day for a fortnight, and afterwards thecond day for another fortnight. and if at any patient is seen at least once a week, and if at any time there is a complaint of mental depression or a craving for drink, the injections are resumed for a few days until the danger is passed. The patients, with one exception, were all treated as out-patients. Most of them took for the first few days a mixture containing capsicum and cinchona, but it is not necessary to continue this after the appetite has returned and the "low feeling" at the stomach has passed away. Even though relapses occurred in several instances, it was found possible to induce the patient to return for further treatment, and this, in more than one case, with a satisfactory result.

$$
1 \text { Brit. Med. Jour., March 3, } 1906 .
$$

\section{PERIODIC VOMITING WITH ACETON. AMIA IN CHILDREN.}

UNDER the above heaciing Dr. Vincent Dickinson describes, in the current number of the "British Journal of Children's Diseases," a form of vomiting which has received a good deal of attention in France and Italy, but not in this country. The clinical picture of the malady as given by the author may be abbreviated as follows: "In the midst of perfect health, without apparent or appreciable cause, or error in diet, or derangement of intestinaI action, the child, who is usually of a nervous or arthritic diathesis, is suddenly seized with vomiting. The vomiting is produced by regurgitation without any premonitory nausea, just as in cases of tuberculous meningitis, the vomit being usually watery, sometimes alimentary or bilious; but when this latter is noticed, which is not often, it indicates that the end of the atack is approaching. Attacks of this kind of vomiting happen several times a day, and recur with variable frequency, sometimes every quarter of an hour. The whole attack lasts usually from two to four or five days, but is sometimes prolonged for two or even three weeks, it being impossible to predict the moment when it will come to an end. Once at an end it leaves no after-effert, and health is re-established without convalescence. After a variable interval of time, a few days to a few months, the attacks of vomiting are renewed with the same symptoms, and the illness may thus continue for years, disappearing completely about the time of puberty.

"The symptoms which are associated with the vomiting are variable. Usually at the onset of the attack the child is prostrate, lies motionless in bed, neither crying nor groaning, its face pale and drawn, the eyes sunken and the abdomen retracted; very often there is constipation, rarely diarrhœa, the tongue is relatively clean, the pulse almost always accelerated, there may be also irregularity. The temperature does not regularly exceed $100.4^{\circ} \mathrm{F}$, very rarely reaching $102.4^{\circ} \mathrm{F}$. In exceptional cases it remains normal. Gastric pain is almost always absent, a point of diagnostic importance; when it does occur it is never at the commencement, but only at the end of the attack, and even then the pain only appears at the moment of vomiting, and ceases in the interval. Thirst is intense, but the child cannot drink, for the least quantity of fluid is sufficient to provoke a fresh attack. The appetite is always retained, an important diagnostic point. To recapitulate, the abrupt onset, the absence of previous gastro-intestinal disturbance, the absence of anorexia, the absence of gastric pain, the character 